\title{
Multimodality Treatment for Early-Stage Hepatocellular Carcinoma: A Bridging Therapy for Liver Transplantation
}

\author{
N. Ashoori ${ }^{a} \quad$ F. Bamberg ${ }^{a} \quad$ P. Paprottka ${ }^{a} \quad$ M. Rentsch ${ }^{b} \quad$ F.T. Kolligs ${ }^{c} \quad$ S. Siegert ${ }^{d}$ \\ A. Peporte $^{a}$ J.A. Al-Tubaikh ${ }^{a}$ M. D'Anastasi ${ }^{a} \quad$ R.T. Hoffmann ${ }^{f} \quad$ M.F. Reiser ${ }^{a}$ \\ T.F. Jakobs ${ }^{\mathrm{e}}$

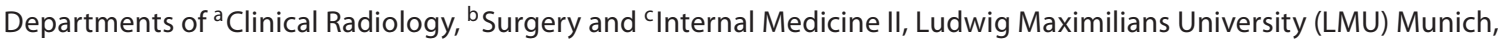 \\ Campus Grosshadern, ${ }^{d}$ Department of Pathology, LMU Munich, Campus Downtown, and e Department of Radiology, \\ Hospital Barmherzige Brueder, Munich, and fDepartment of Radiology, University Hospital Carl Gustav Carus, \\ Dresden, Germany
}

\section{Key Words}

Liver - Hepatocellular carcinoma - Radiofrequency ablation • Transcatheter arterial chemoembolization • Bridging therapy · Liver transplantation

\section{Abstract \\ Purpose: To evaluate the efficiency of a multimodality ap- proach consisting of transcatheter arterial chemoemboliza- tion (TACE) and radiofrequency ablation (RFA) as bridging therapy for patients with hepatocellular carcinoma (HCC) awaiting orthotopic liver transplantation (OLT) and to evalu- ate the histopathological response in explant specimens. Materials and Methods: Between April 2001 and November 2011, 36 patients with $50 \mathrm{HCC}$ nodules $(1.4-5.0 \mathrm{~cm}$, median $2.8 \mathrm{~cm}$ ) on the waiting list for liver transplantation were treat- ed by TACE and RFA. The drop-out rate during the follow-up period was recorded. The local efficacy was evaluated by his- topathological examination of the explanted livers. Results: During a median follow-up time of 29 (4.0-95.3) months the cumulative drop-out rate for the patients on the waiting list was $0,2.8,5.5,11.0,13.9$ and $16.7 \%$ at $3,6,12,24,36$ and 48 months, respectively. 16 patients (with $26 \mathrm{HCC}$ lesions) out of $36(44.4 \%)$ were transplanted by the end of study with a me-}

dian waiting list time of 13.7 (2.5-37.8) months. The histopathological examination of the explanted specimens revealed a complete necrosis in 20 of $26 \mathrm{HCCs}(76.9 \%)$, whereas 6 (23.1\%) nodules showed viable residual tumor tissue. All transplanted patients are alive at a median time of 29.9 months. Imaging correlation showed $100 \%$ specificity and $66.7 \%$ sensitivity for the depiction of residual or recurrent tumor. Conclusion: We conclude that TACE combined with RFA could provide an effective treatment to decrease the drop-out rate from the OLT waiting list for HCC patients. Furthermore, this combination therapy results in high rates of complete tumor necrosis as evaluated in the histopathological analysis of the explanted livers. Further randomized trials are needed to demonstrate if there is a benefit in comparison with a single-treatment approach.

Copyright $\odot 2012$ S. Karger AG, Basel

\section{Introduction}

Hepatocellular carcinoma (HCC) is the fifth most common cancer worldwide and is the second leading cause of cancer mortality worldwide [1]. The major risk factor for developing HCC is chronic liver disease and

\section{KARGER}

Fax +4161306 1234

E-Mail karger@karger.ch

www.karger.com (c) 2012 S. Karger AG, Basel

0012-2823/12/0864-0338\$38.00/0

Accessible online at:

www.karger.com/dig
Nima Ashoori, MD

Department of Clinical Radiology, LMU Munich, Campus Grosshadern

Marchioninistrasse 15

DE-81377 Munich (Germany)

E-Mailn.ashoori@radiologie-ukw.de 
cirrhosis, which is present in $70-90 \%$ of patients [2]. The major causes of cirrhosis in patients with HCC include hepatitis B (HBV) and hepatitis C infections (HCV), followed by alcoholic liver disease and non-alcoholic steatohepatitis [3]. Because of the widespread incidence of hepatitis B and C, HCC continues to increase in both the USA and Europe [4].

Before the advent of transplantation, liver resection was the only method to achieve cure. However, resection is associated with substantial morbidity and mortality, and many patients do not have sufficient hepatic reserve to tolerate removal of enough hepatic mass to achieve complete tumor resection with disease-free tissue margins [4].

Orthotopic liver transplantation (OLT) is an effective treatment for both tumor and underlying cirrhosis and is considered the best therapeutic option in selected patients [5]. Transplantation is unusual among therapeutic procedures because the need exceeds the availability and this therapy cannot be offered immediately. The consequence of the shortage of donors and the increasing demand for donor organs is an increased waiting time for patients listed for OLT [6]. Out of the total number of patients with HCC on the waiting list, $20-30 \%$ have substantial disease progression while still awaiting OLT, leading to removal from the waiting list [1-3]; in order to reduce progression, patients are commonly considered for local treatment while awaiting OLT [7].

In 1996, Mazzaferro et al. [8] demonstrated that patients meeting the criteria of a single lesion $\leq 5 \mathrm{~cm}$ or up to three lesions measuring $\leq 3 \mathrm{~cm}$ each (subsequently referred to as the Milan criteria) have optimal post-OLT outcomes with lowest rates of recurrence and overall survival indistinguishable from that of OLT recipients without a history of HCC [8]. The limited supply of donor livers and the resulting long waiting list time leads to drop-out from candidacy due to tumor progression in a significant proportion of patients who initially met surgical criteria. Increasing tumor burden during a long waiting time may also adversely affect post-OLT survival rates [9].

Recent advances in interventional radiologic techniques have allowed patients to be maintained within the Milan criteria or to be downstaged to fall within the Milan criteria [10] in order to remain or to become eligible for OLT. Radiofrequency ablation (RFA) has been shown to be effective in a small sample of patients in the USA and in Europe [11, 12]. Recently, Bruix and Sherman [13] illustrated the use of intra-arterial radioembolization with ${ }^{90} \mathrm{Y}$ microspheres as a bridge to transplantation or resection.
Transcatheter arterial chemoembolization (TACE), however, remains perhaps the most commonly used palliative therapy for unresectable HCC in patients who are awaiting OLT as well as those who are not transplant candidates $[13,14]$. TACE was examined as a potentially effective downstaging modality in a recent study in Europe [15] and in another study in the USA [16].

In our retrospective analysis, we evaluated the effect of a multimodality approach consisting of TACE and RFA on the outcome of patients on the waiting list. Further we evaluated the local efficacy of such a multimodality approach by analysis of histopathological results of the explanted livers. Evidence suggests that TACE combined with RFA have a synergistic effect [17-20] in treating HCC and might be superior to TACE or RFA alone in terms on the effect of survival $[21,22]$. The decrease of blood flow in the HCC lesion by TACE appears to increase the efficacy of RFA in destroying tumors [23, 24]. Furthermore, we investigated whether the synergistic effect of this multimodality approach leads to a lower dropoff rate of HCC patients from the OLT waiting list and to a higher rate of complete necrosis in the treated HCC nodules.

\section{Material and Methods}

\section{Patients}

Between April 2001 and November 2011, 44 patients with HCC were first listed for liver transplantation. Of the 44 patients, 8 did not have a complete follow-up and were excluded from the study. The remaining 36 patients ( 29 men, 7 women; aged $42-71$ (mean 59.2) years) were treated with a multimodality treatment approach (TACE followed by RFA) before OLT. 26 patients had solitary HCC, 6 patients had two nodules and 4 patients had three nodules. All patients fulfilled the Milan criteria prior to the first combined therapy. 34 patients presented with Child-Pugh A cirrhosis and 2 patients with Child-Pugh B cirrhosis.

According to the Barcelona Clinic Liver Cancer (BCLC) staging and treatment algorithm, 34 patients presented with earlystage HCC (BCLC stage A) while 2 patients were stratified as BCLC stage 0 patients (very-early-stage HCC). The reason for a locoregional therapy instead of a surgical resection for the 2 patients with resectable HCCs was that the patients refused to undergo surgery or lesion location deemed unfeasible for surgical resection. The diagnosis of HCC was confirmed by imaging techniques according to the European Association for Study of the Liver consensus conference criteria. In 3 patients a biopsy was necessary due to vague imaging findings.

The total number of HCCs in all patients was 50 with a maximum diameter that varied from 1.4 to $5.0 \mathrm{~cm}$ (mean $2.8 \pm 0.6$, median 2.6). Written informed consent was obtained from all patients before treatment. 
The cause of liver cirrhosis was: HCV infection in 20 patients, $\mathrm{HBV}$ infection in 5 patients, alcohol-induced cirrhosis in 7 patients, and cryptogenic in 4 patients. The decision to implement neoadjuvant therapy was made in a multidisciplinary liver tumor management conference attended by transplant surgeons, surgical oncologists, hepatologists, radiologists and liver pathologists. Patients listed for OLT with at least one HCC nodule $>2 \mathrm{~cm}$ and an anticipated waiting time of more than 3 months were considered for neoadjuvant therapy. Two patients with HCC nodules $<2 \mathrm{~cm}$ refused surgical therapy prior to transplantation.

Patients were referred for transplant evaluation if they were not resectable but met the Milan criteria. Patients who fulfilled the transplant criteria were treated with the intent to bridge them to transplantation. At our institution the following algorithm for the treatment selection was usually respected: if the lesion was between 2 and $5 \mathrm{~cm}$ or if patients had more than one lesion, the patient had TACE followed by RFA. During the previously mentioned period, 36 patients were referred to a combined therapy consisting of TACE followed by RFA.

A prerequisite for locoregional treatment was a sufficient blood clotting status with a partial thromboplastin time $<40 \mathrm{~s}$, INR $<1.75$, and a platelet count $>40,000 / \mathrm{mm}^{3}$. As part of the pretreatment work-up, CT examinations with a multiphasic protocol (contrast flow rate $5 \mathrm{ml} / \mathrm{s}$ (unenhanced, arterial, portal-venous and late phases)) were performed in each patient using multidetector scanners. In addition, prior to the tumor management conference, a contrast medium-enhanced MRI examination was performed in all patients (fig. 1a, b, 2a).

\section{Conventional Transcatheter Arterial Chemoembolization}

Prior to RFA a conventional Lipiodol-based (max. $10 \mathrm{ml}$ ) TACE with a chemotherapeutic drug (epirubicin hydrochloride) was performed in each patient. Calibrated microspheres (diameter $250 \mu \mathrm{m}$ ) were added in those patients where the Lipiodol did not devascularize the HCC nodule completely. Angiography was performed by way of a transfemoral approach in all patients.

After superselective catheterization of the hepatic and tumorfeeding arteries, an emulsion consisting of $50 \mathrm{mg}$ epirubicin hydrochloride (Farmorubicin ${ }^{\circledR}$; Pfizer Pharma) and max. $5 \mathrm{ml}$ iodized oil (Lipiodol ${ }^{\circledR}$ Ultra-Fluid; Guerbet) were slowly infused under fluoroscopic guidance until stasis within the HCC lesion or the tumor-feeding vessel was reached. Calibrated polyvinyl alcohol particles (Bead Block ${ }^{\circledR}$; Biocompatibles International, Farnham, UK) or other microspheres (Embozene ${ }^{\circledR}$; Celonova Biosciences, Atlanta, Ga., USA) were applied to achieve complete stasis in the tumor if necessary. Patients were carefully observed during the entire procedure, and analgesics and antiemetics were administered on demand.

\section{Radiofrequency Ablation}

A more detailed description of the RFA procedures at our institution is depicted elsewhere [25]. After multiphase contrastenhanced computed tomography (CT) was performed, the optimal electrode pathway to the HCC lesion was determined. In cases of HCC nodules with critical anatomical locations or lesions that are not amenable to US, a CT-fluoroscopy guidance was performed. The exact positioning of the electrode and the complete coverage of the lesion with the hooks fully distended was warranted by CT-/CT-fluoroscopy guidance (fig. 2b), or when there was doubt, with additional contrast-enhanced CT scans. For
HCCs $<3 \mathrm{~cm}$ in size, a single session of ablation with a maximum electrode diameter of $5 \mathrm{~cm}$ was used to provide a sufficient safety margin. In larger lesions, the electrode was repositioned several times in a single session in order to achieve a volume large enough to cover the entire HCC including a safety margin. To reduce the risk of puncture-related bleeding, electrode-track ablation was performed after completion of the procedure at a reduced power level. Our standard approach for RFA was to perform the procedure under moderate sedation and local anesthesia. The majority of ablations were performed with administration of a combination of midazolam maleate, parecoxib sodium and piritramide. Blood pressure, heart rate and oxygen saturation were monitored continuously. In patients who presented with low tolerance to pain, or lesions that were difficult to target, the procedure was performed under general anesthesia. Preinterventional antibiotics were used for all patients.

\section{Liver Transplantation}

According to the Eurotransplant indication guidelines for liver transplantation to treat HCC, all patients revealed a disease pattern within the Milan criteria at the beginning of their treatment. In general, liver transplantations were carried out using a 'piggyback' technique with preservation of the vena cava as a classic piggyback technique (either end-to-side or side-to-side cavocavostomy), as this represents our center's standard. Solely in selected cases, according to anatomic prerequisites and the subjective considerations of the surgeon, a vena cava resection was performed with subsequent in situ transplantation of the graft. Arterial reconstruction was intended as anastomosis between the donor and recipient junctions of the hepatic and gastroduodenal artery. Other arterial reconstructions represented rare exceptions.

\section{Follow-Up}

The efficacy of the therapy was determined using contrastenhanced CT or MR scans obtained 6-8 weeks (fig. 1c, d, 2c) and then every 3 months after combined locoregional therapy. In the 16 transplanted patients the follow-up was performed by contrast medium-enhanced (Gd-EOB-DTPA disodium (Primovist)/Ferucarbotran (Resovist, until 2007)) MRI examinations. The MRI examinations were conducted in high-field scanners (Magnetom Sonata $^{\circledR}(1.5 \mathrm{~T})$, Magnetom Avanto ${ }^{\circledR}(1.5 \mathrm{~T})$ and Magnetom Verio $^{\circledR}(3 \mathrm{~T})$, Siemens ${ }^{\circledR}$, Forchheim, Germany) and were, among others, composed of a dynamic phase and an accumulation phase. The treatment sessions were repeated if viable tumor tissue was depicted during the follow-up.

\section{Pathological Examination of the Explant Specimens}

Each explanted liver was carefully examined by two pathologists for number of tumor nodules and percentage of tumor necrosis. The explanted livers were serially sectioned and the number, diameter and location of neoplastic nodules were recorded. All hematoxylin and eosin (HE)-stained sections taken at the time of processing were evaluated. The percentage of tumor necrosis was assessed in each tumor nodule based on these sections, which in some cases did not represent the entire tumor.

\section{Statistical Analysis}

Descriptive statistics are provided as mean \pm SD for continuous variables and absolute and relative frequencies for categorical 

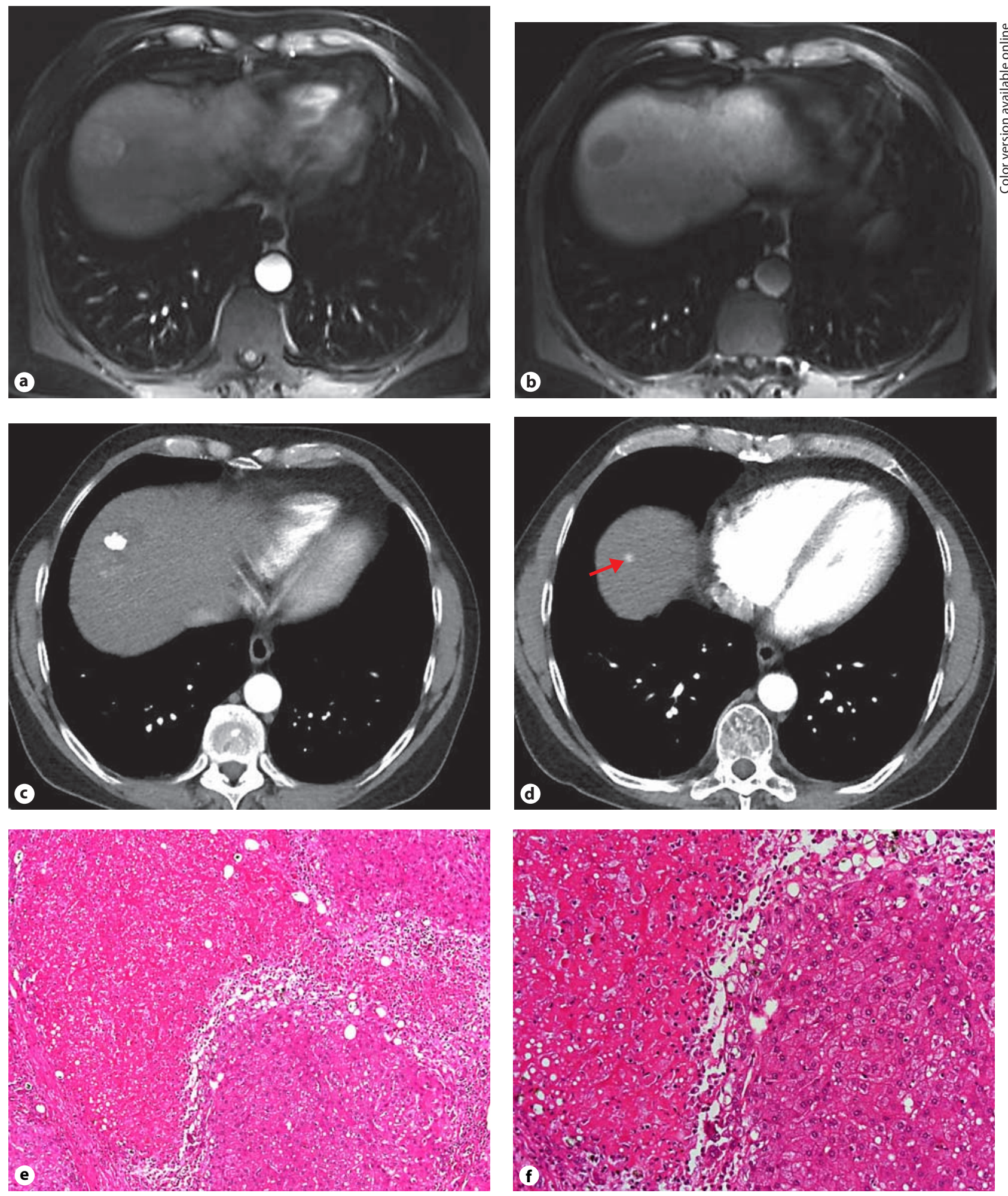

Fig. 1. Images of a 57-year-old man with hepatitis C-induced cirrhosis and multifocal HCC. Contrast medium-enhanced MRI of a HCC nodule in segment VIII prior to the locoregional therapy in the arterial phase (a) and in the accumulation phase (b). Axial CT view of the arterial phase 6 weeks after TACE/RFA (c) with residual viable tumor (arrow) proximal to the ablation area (d). e 6 months after the first locoregional therapy a histological slice (HE stain) of a lesion in segment VIII shows a largely necrotic area. $\mathbf{f}$ In the higher magnification bordering regions of viableappearing tumor to the right are shown. 

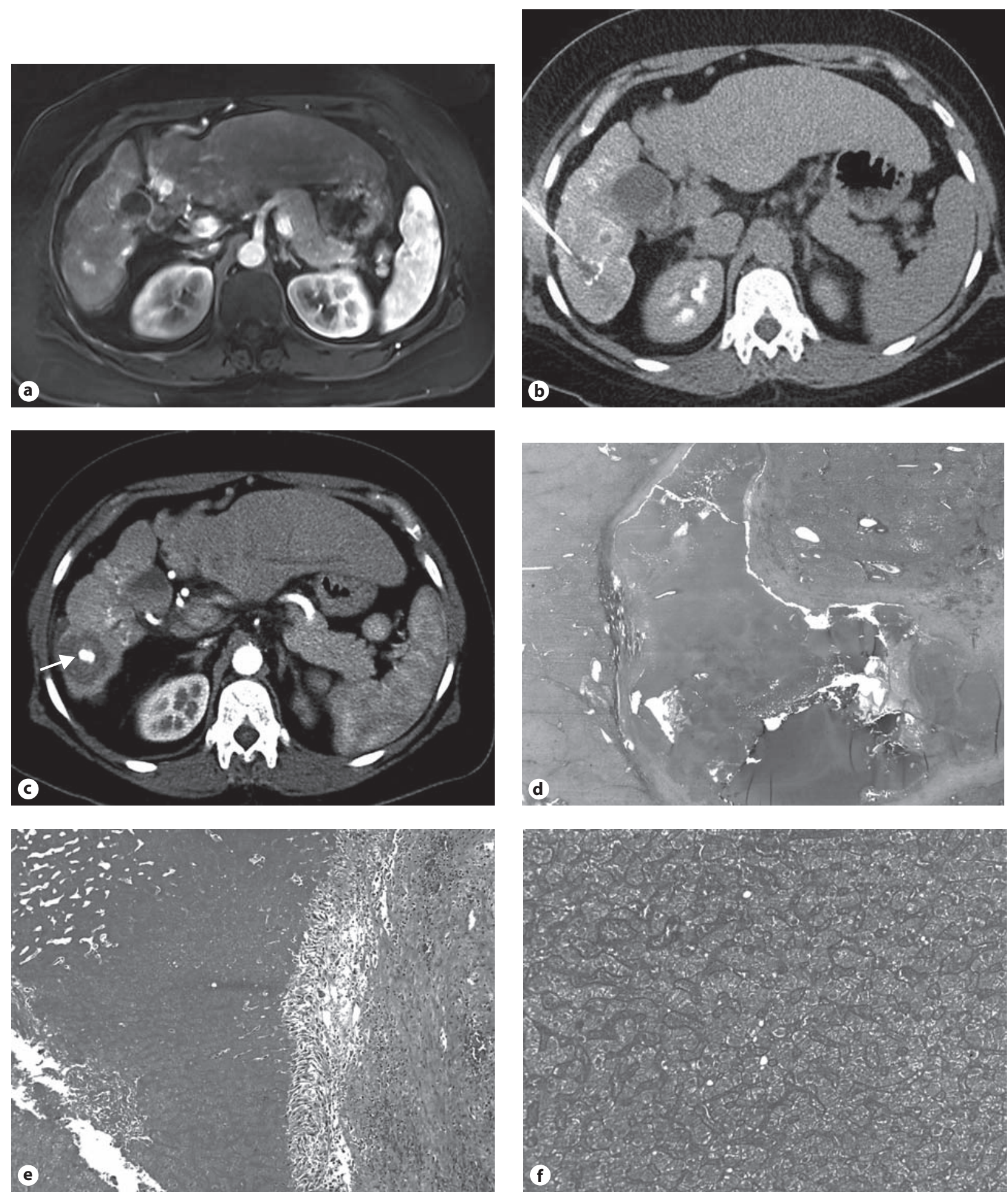

Fig. 2. Images of a 42-year-old woman with hepatitis $\mathrm{C}$ and multifocal HCC. a Contrast-enhanced axial MRI view in the arterial phase reveals a HCC nodule in liver segment VI. b During the RFA procedure with RFA needle in the HCC nodule. c Contrastenhanced transverse CT image (arterial phase) obtained 6 weeks after locoregional therapy showing an ablation area with central Lipiodol storage (arrow) and without any visible viable and con- trast-enhancing tumor tissue. Histological slices (HE stain) 12 months after locoregional therapy demonstrate complete necrosis of the HCC nodule with coagulative necrosis surrounded by fibrous pseudocapsula (d) and histiocytic reactions in the periphery (e). $\mathbf{f}$ The highest magnification depicts preservation of hepatocyte architecture with homogeneous hypereosinophilic cytoplasm and loss of normal nuclear elements. 
Table 1. Characteristics of the transplanted patients

\begin{tabular}{|c|c|c|c|c|c|c|c|c|}
\hline $\begin{array}{l}\mathrm{Pa}- \\
\text { tient }\end{array}$ & $\begin{array}{l}\text { Age/ } \\
\text { sex }\end{array}$ & $\begin{array}{l}\text { Nod- } \\
\text { ules } \\
\mathrm{n}\end{array}$ & $\begin{array}{l}\text { Waiting } \\
\text { time } \\
\text { months }\end{array}$ & $\begin{array}{l}\text { TACE } \\
\mathrm{n}\end{array}$ & $\begin{array}{l}\text { RFA } \\
\mathrm{n}\end{array}$ & $\begin{array}{l}\text { Tumor } \\
\text { size } \\
\mathrm{cm}\end{array}$ & $\begin{array}{l}\text { Necro- } \\
\text { sis } \\
\%\end{array}$ & $\begin{array}{l}\text { TNM } \\
\text { stage }\end{array}$ \\
\hline 1 & $47 / \mathrm{M}$ & 1 & 6.3 & 3 & 1 & 2.5 & 100 & 2 \\
\hline 2 & $50 / \mathrm{M}$ & 3 & 8.3 & 4 & 1 & $\begin{array}{l}3.8 \\
3.4 \\
1.6\end{array}$ & $\begin{array}{r}90 \\
100 \\
100\end{array}$ & 2 \\
\hline 3 & $57 / \mathrm{M}$ & 2 & 24.5 & 1 & 1 & $\begin{array}{l}2.5 \\
2.0\end{array}$ & $\begin{array}{r}100 \\
75\end{array}$ & 2 \\
\hline 4 & $60 / \mathrm{M}$ & 2 & 9.0 & 1 & 1 & $\begin{array}{l}3.5 \\
1.7\end{array}$ & $\begin{array}{l}100 \\
100\end{array}$ & 2 \\
\hline 5 & $58 / \mathrm{M}$ & 3 & 19.3 & 2 & 2 & $\begin{array}{l}3.6 \\
2.7 \\
1.9\end{array}$ & $\begin{array}{r}85 \\
100 \\
100\end{array}$ & 2 \\
\hline 6 & $49 / \mathrm{M}$ & 1 & 5.2 & 1 & 1 & 3.7 & 100 & 2 \\
\hline 7 & $62 / \mathrm{M}$ & 1 & 22.2 & 1 & 1 & 1.9 & 100 & 1 \\
\hline 8 & $51 / \mathrm{M}$ & 1 & 4.6 & 1 & 1 & 1.6 & 90 & 1 \\
\hline 9 & $48 / \mathrm{M}$ & 1 & 11.0 & 1 & 1 & 2.8 & 80 & 2 \\
\hline 10 & $57 / \mathrm{M}$ & 2 & 7.34 & 1 & 1 & $\begin{array}{l}2.8 \\
1.4\end{array}$ & $\begin{array}{l}100 \\
100\end{array}$ & 2 \\
\hline 11 & $42 / \mathrm{F}$ & 2 & 11.5 & 2 & 2 & $\begin{array}{l}1.6 \\
1.5\end{array}$ & $\begin{array}{l}100 \\
100\end{array}$ & 2 \\
\hline 12 & $54 / \mathrm{M}$ & 1 & 33.7 & 5 & 2 & 2.3 & 100 & 2 \\
\hline 13 & $63 / \mathrm{M}$ & 1 & 13.2 & 1 & 1 & 1.7 & 100 & 1 \\
\hline 14 & $55 / \mathrm{F}$ & 2 & 18.3 & 3 & 1 & $\begin{array}{l}3.2 \\
1.6\end{array}$ & $\begin{array}{l}100 \\
100\end{array}$ & 2 \\
\hline 15 & $57 / \mathrm{M}$ & 1 & 7.3 & 4 & 2 & 2.8 & 80 & 2 \\
\hline 16 & $58 / \mathrm{M}$ & 2 & 15.2 & 1 & 1 & $\begin{array}{l}2.7 \\
2.7\end{array}$ & $\begin{array}{l}100 \\
100\end{array}$ & 2 \\
\hline
\end{tabular}

variables. Conventional measures of diagnostic accuracy (sensitivity, specificity, positive and negative predictive value (PPV and NPV, respectively)) were derived using histology as the gold standard. Associated 95\% confidence intervals (CI) were calculated using the binominal distribution. Finally, survival curves and median survival as well as pertaining 95\% CI were estimated by the Kaplan-Meier method and group comparisons were made by log-rank test statistics. All analyses were performed by SAS version 9.2 (SAS Institute, Inc., Cary, N.C., USA) and a two-sided p value of 0.05 was considered to indicate statistical significance.

\section{Results}

Thirty-six patients underwent combined neoadjuvant therapy consisting of TACE before RFA while on the waiting list for liver transplantation. The majority of subjects were men $(80.5 \%)$, the mean age of all patients was 58 years ( \pm 6.7 , median 59.2 ). All patients received multi-
Table 2. Comparison of the last imaging procedure in the followup with histologic findings

\begin{tabular}{llcr}
\hline \multirow{2}{*}{ Imaging findings } & \multicolumn{2}{l}{ Histologic findings } \\
\cline { 2 - 4 } & positive & negative & total \\
\hline Positive & 4 & 0 & 4 \\
Negative & 2 & 20 & 22 \\
\hline Total & 6 & 20 & 26 \\
\hline
\end{tabular}

modality HCC treatment with a mean of $2.0 \pm 1.6$ procedures per patient. Five out of the 16 transplanted patients received more TACE treatment sessions than RFA treatment sessions, as shown in table 1 . All these patients have had only TACE therapies prior to the combined therapy.

The treatment sessions were repeated in 4 patients due to the recurrence of HCC, depicted by MRI scans during the follow-up. According to the SIR guidelines [26], no major complications were observed. The most common postprocedure morbidity was postembolization syndrome, consisting of fatigue, mild nausea, low-grade fever, and abdominal pain that was easily managed with oral analgesics and antiemetics. In $8 \%$ of the cases there was slight subcapsular bleeding after RFA with neither clinical symptoms nor progression in an additional CT scan performed the day after RFA. Between diagnosis of HCC and the first treatment there was a median time interval of 37.5 days (range 3-1,433, mean $108.4 \pm$ 109.4.1). The median time interval between TACE and RFA was 1 day (range $0-20$, mean $3.2 \pm 2.7$ ). The median time on the waiting list was 27.4 months (range 4.0-95.3, mean 29 $\pm 16.6) .16$ of the $36(44.4 \%)$ patients were transplanted until the end of the study (November 2011).

Transplanted patients showed a median time of 11.3 months (range 4.6-33.8, mean $13.5 \pm 6.5$ ) between the time of the initial diagnosis and date of transplantation (table 2). Without the transplanted patients the median time on the waiting list was 37.8 months (range 6.1-95.3, mean $40.5 \pm 14.9$ ). There were 2 cases of HCC and cirrhosis-related deaths among the listed patients 29 and 36 months after initial diagnosis. Four patients were listed and removed (drop-out) from the transplant waiting list at $6,16,22$ and 46 months, respectively, due to tumor progression. Two patients died after 6.5 and 30 months of waiting time on the list because of liver failure. The intention-to treat drop-out rate was $0,2.8,5.5,11.0,13.9$ and $16.7 \%$ at $3,6,12,24,36$ and 48 months, respectively. A 
detailed characterization of the drop-out patients is displayed in table 3. The mean age of the drop-out patients is $64.5( \pm 5.67)$ years and is above the mean age (58.79 \pm 6.43 years) of the follow-up patients.

The other parameters (Child-Pugh and BCLC) failed to show any significant differences. The drop-out patients showed a median time on the waiting list of 19 months (mean $20.92 \pm 11.75$ ). This is even below the average of the follow-up patients (see above). 16 patients received full-size OLT and the transplantation was performed according to standardized procedures. Due to a chronic rejection reaction in 1 case a retransplantation was required after 11 months which was performed successfully. The remaining transplanted patients experienced an uneventful postoperative period. All transplanted patients were alive at a median time of 29.9 months (range 10.6-62.9, mean $35.6 \pm 11.6$ ) after OLT and there was no evidence of recurrent HCC at follow-up.

\section{Histological Findings in the Explant Specimens}

(table 1)

In concordance with the imaging studies during follow-up 26 nodules were found in the 16 explanted livers. The diameter ranged between 1.4 and $3.8 \mathrm{~cm}$ with a median of $2.5 \mathrm{~cm}$ (mean $2.4 \pm 0.65 \mathrm{~cm}$ ). Two pathologists performed an independent review of the histological slides of the HCC nodules in the explants. All nodules had been treated by at least one session TACE and one session RFA (table 1).

Of 26 nodules, $20(76.9 \%$, mean diameter $2.3 \mathrm{~cm})$ demonstrated complete necrosis (fig. 2e, f), whereas $6(23.1 \%$, mean diameter $2.8 \mathrm{~cm}$ ) nodules showed viable residual tumor tissue (fig. 1e, f). Coagulative-type necrosis was seen in all cases. In nodules showing partial necrosis the non-necrotic portion of the tumor was located peripherally, with the central area showing complete necrosis. The portion of viable tumor tissue was estimated by the pathologist and ranged between 5 and $25 \%$ of the whole lesion.

\section{Correlation between the Last Follow-Up MRI}

Examination of the Transplanted Patients and the

\section{Pathological Outcome}

The mean interval between the last imaging procedure and transplantation was 1.3 months. All patients underwent gadolinium-enhanced MRI. A positive result in the imaging procedure was moderately sensitive for the detection of residual or recurrent tumor as determined by histology (sensitivity 66.7\%, 95\% CI 22.2-95.7) but correctly ruled out the presence of viable tumor in all cases
Table 3. Baseline characteristics of the drop-out patients

\begin{tabular}{lllllll}
\hline $\begin{array}{l}\text { Pa- } \\
\text { tient }\end{array}$ & Gender & Age & $\begin{array}{l}\text { Child- } \\
\text { Pugh }\end{array}$ & BCLC & $\begin{array}{l}\text { Time on waiting } \\
\text { list, months }\end{array}$ & Cause \\
\hline 1 & M & 65 & A & A & 6.0 & T \\
2 & M & 51 & B & A & 6.5 & D \\
3 & M & 68 & A & A & 22 & T \\
4 & M & 57 & B & A & 30 & D \\
5 & M & 70 & A & A & 16 & T \\
6 & M & 64 & A & A & 46 & T \\
\hline
\end{tabular}

$\mathrm{T}=$ Tumor progression; $\mathrm{D}=$ death .

(specificity 100\%, 95\% CI 83.0-100). Thus, while the positive imaging finding was excellent in predicting the presence of viable tumor (PPV 100\%, 95\% CI 40.0-100), the NPV was high $(90.9 \%, 95 \%$ CI 70.8-99.0) due to the low prevalence of disease (23\%).

\section{Analysis of the Survival Data of the Non-Transplanted Patients}

There was a trend towards longer survival in subjects with complete remission but no statistically significant difference as compared to subjects with partial response (residual or recurrent tumor) on baseline imaging, certainly attributable to sample size (mean survival in subjects with partial response: 27.4 months, 95\% CI 21.2-33.6 months; fig. 3a). There was also no significant difference between the survival of transplanted patients (mean 40.5 months, 95\% CI 38-43) compared with non-transplanted patients (30.4 months, 95\% CI 29.1-31.7; fig. 3b).

\section{Discussion}

Liver transplantation has become a widely accepted therapy for HCC patients with tumor burdens within guidelines, generally either the Milan or University of California, San Francisco, criteria. Transplantation is the only treatment option that cures both the HCC and the underlying cirrhosis. It is especially efficient in earlystage HCCs, which has been demonstrated in various studies $[8,27,28]$. Despite these results, transplantation is unusual among therapeutic procedures as the need exceeds availability of transplant organs and therefore OLT cannot be provided immediately when HCC is diagnosed. The shortage of organs results in a waiting time in which the phenotype of the disease may change with a 
Fig. 3. a Survival by imaging response. b Survival of transplanted patients compared with non-transplanted patients.
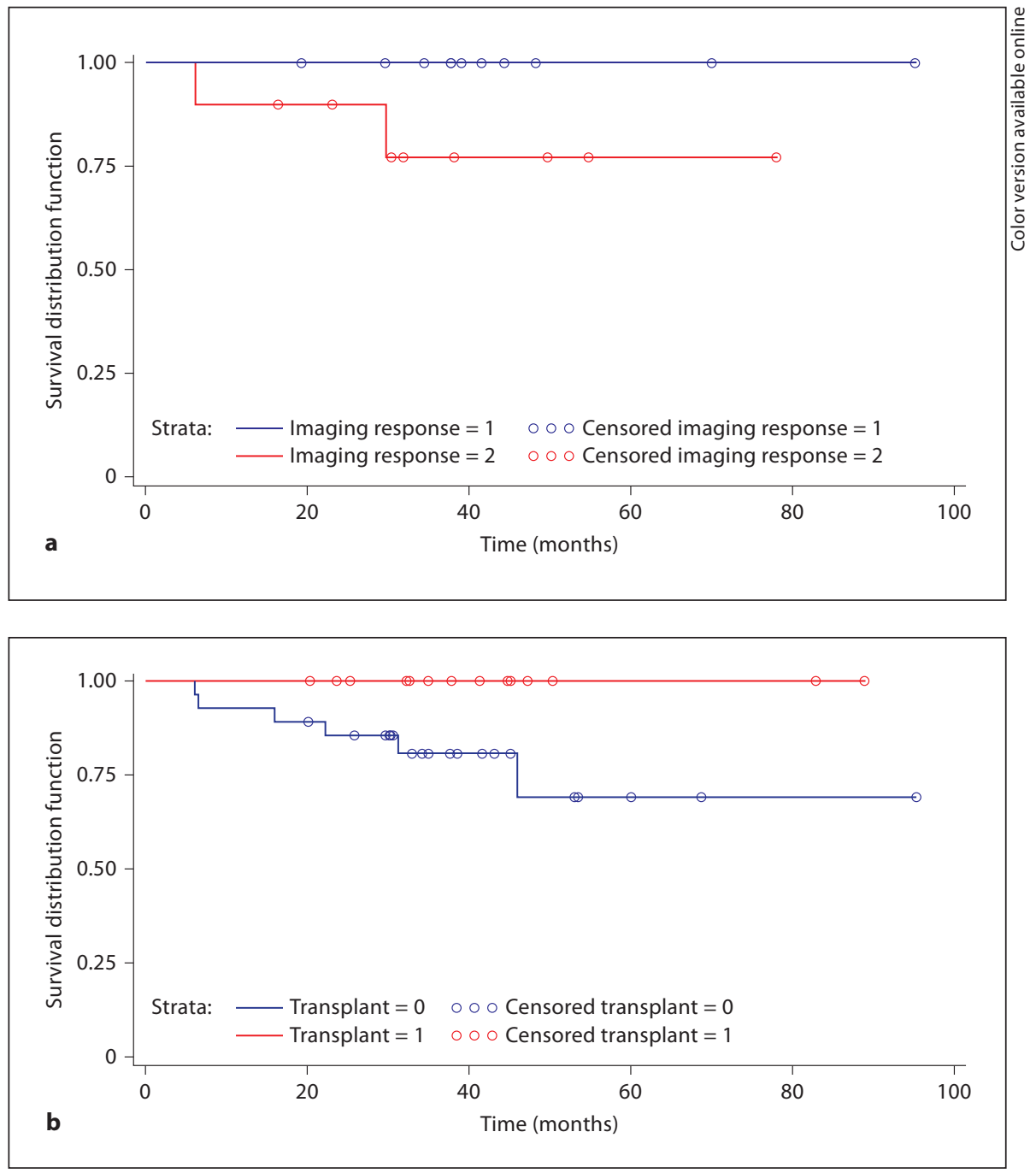

possible drop-out from the waiting list. The incidence of disease progression while listed for organ replacement is $10-23 \%[29,30]$.

Data from single-center experiences and Markov model analyses $[9,31]$ set the risk of tumor progression at 3 months at 8 and $15 \%$ for very-early-stage and earlystage HCC, respectively. Comparing this to our results with no patient showing progressive disease at 3 months but 4 patients showing progressive tumor burden at a later point during follow-up, it appears that the use of a multimodality treatment approach provides a benefit for the patients. According to United Network of Organ Sharing data [32] the drop-out rate for patients with HCC in cirrhosis on the waiting list is $8.7,16.9$, and $31.8 \%$ at 3,6 and 12 months, respectively. These numbers are substantially higher compared to the favorable results we can report from our retrospective analysis with a drop-out rate of 0 , 2.8 and $5.5 \%$ after 3, 6 and 12 months, respectively. This represents a strong indication that multimodality treatment for HCC is an effective tool for bridging patients awaiting transplantation.

Freeman et al. [32] demonstrated that in case of HCC the drop-out rate is higher compared to the drop-out rate observed for non-malignant diseases, which again supports the utilization of locoregional therapies to decrease the drop-out rate by preventing progression of disease. The efficacy of locoregional therapy has been shown in previous studies. In conformity with this, the American Association for the Study of the Liver practice guidelines [13] state that local ablation is a safe and effective therapy for patients who cannot undergo resection, or as a bridge to transplantation. Lu et al. [11] reported the outcome of 
52 consecutive patients accepted for OLT and treated with percutaneous RFA and revealed a drop-out rate of $5.8 \%$ after 12 months while on the waiting list. This reported drop-out rate matches our drop-out rate of 5.5\% after 12 months in a patient cohort of the same size we are reporting on in the analysis. This illustrates that these published drop-out rates are reproducible among various centers using locoregional therapies for bridging.

Other studies with RFA as a single modality therapy prior to OLT vary in their results. In a prospective study with 50 consecutive patients treated with RFA prior to OLT, Mazzaferro et al. [12] reported a drop-out rate of $0 \%$ after a mean waiting time of 9.5 months. This is superior to the results in our study, although the patient population in both studies is similar. On the other hand, in another study from 2002 by Fontana et al. [33] there is a drop-out rate of $21 \%$ during a mean waiting time of 7.9 months among 33 patients treated with RFA prior to OLT.

In another prospective study, Cillo et al. [34] analyzed the drop-out probability of 100 listed patients treated with locoregional therapy prior to liver transplantation and revealed a drop-out rate of 6,11 and $25 \%$ at 6,12 and 24 months, respectively. These values are higher than reported in our study, most likely because of a bias in the selection criteria. Our analysis also included 4 very-early-stage HCC patients according to the BCLC criteria, which might have an impact on our results. A further study by Cillo et al. [34] contained 40 patients, which exceeded the Milan criteria; however, in our study all included patients met the Milan criteria. In another study, Maddala et al. [35] revealed in 54 listed HCC patients who underwent chemoembolization prior to OLT a drop-out rate of 15 and $25 \%$ at 6 and 12 months, respectively. These results are inferior to our results, indicating that the combined use of TACE and RFA provides additive benefit to the patients.

Most studies that assessed the benefit of RFA pre-OLT $[11,12,16,28,33,36]$ demonstrated a decrease in the drop-out rate compared with untreated HCC patients [32], whereas a meta-analysis by Lesurtel et al. [37] assessed the impact of TACE as a neoadjuvant therapy prior to OLT for HCC. They demonstrated no sufficient evidence of benefits when TACE is used before transplantation. Experiences with combined therapies such as TACE followed by RFA $[24,25,38,39]$ resulted in a higher local tumor control rate due to the higher rates of complete tumor necrosis. This is also in line with our results of the histopathological evaluation of the HCC nodules of liver explants. Our histopathological evaluation depicted a high rate of complete necrosis in $75 \%$ of the 24 nodules. Lu et al. [11] measured the effectiveness of RFA in HCCs on the basis of histological findings in 24 explanted livers and obtained a complete necrosis rate of $74 \%$ to similar results. Marin et al. [40] measured the local efficacy of various interventional neoadjuvant treatment methods in explanted livers and found a complete necrosis rate of only $10 \%$. Although complete tumor necrosis is desirable, also an incomplete tumor necrosis is able to reduce the size of the tumor and may confine disease progression and thereby improve outcome, particularly in patients awaiting liver transplantation. In any case, a standardized histopathological analysis is needed to compare the local efficacy of a single-treatment approach to multimodality treatment consisting of TACE and RFA.

In this context, the question arises how TACE and RFA should be sequenced. The advantage of TACE prior to RFA is the reduced heat sink effect with the ability to create larger ablation zones more easily. The advantage of using TACE after RFA is that RFA generates a hyperemic rim surrounding the ablation area, which then can consequently be targeted by transarterial means more effectively. Further studies need to clarify how locoregional treatment options should be implemented in the treatment paradigm of non-resectable HCC.

With drop-out rates of $0,2.8,5.5,11.0,13.9$ and $16.7 \%$ after $3,6,12,24,36$ and 48 months, respectively, as reported in our analysis, there appears to be a clear decrease of drop-out rates compared with untreated HCC nodules [32] and to many previously discussed results of studies with RFA and especially TACE as the sole bridging treatment $[11,34,35]$. Especially in the studies with RFA as the single-treatment method there is a high variation among different studies, as mentioned above, and it remains unclear if there is a significant benefit of a multimodality approach in comparison to RFA alone.

Our results warrant randomized prospective studies to compare the multimodality treatment versus single modality approach. Moreover, standardized histopathological analysis would also contribute to a more reproducible assessment of the local efficacy of various applied treatment methods. Finally, in concordance with the study by Lu et al. [11], imaging correlation showed $100 \%$ specificity for the detection for residual or recurrent tumor. On the other hand, a positive result in the imaging procedure was with $66.7 \%$ moderately sensitive for the detection of residual or recurrent tumor. This sensitivity was higher than that obtained by Lu et al. (sensitivity $36 \%$ ) which could be attributed to the different imaging modalities used in the follow-up.

In our study all transplanted patients were examined by gadolinium-enhanced MRI, whereas in the study by 
Lu et al. [11] almost $96 \%$ of the patients were examined by contrast-enhanced CT. Dromain et al. [41] showed already in a study from 2002 that MRI has an edge over CT in detecting viable HCC tumors after being treated with RFA. An analysis of the survival of the non-transplanted patients depicted a trend toward longer survival in patients with complete remission on imaging. There is also a trend toward longer survival of transplanted patients compared with non-transplanted patients. Both analyses failed to reach statistical significance, which could be attributed to the small patient population. These tendencies should be confirmed by performing further studies with a higher number of subjects.

There are various limitations as our study is a retrospective single-center study and as in comparison to most other studies there is a selection bias towards patients with a lower tumor burden in our study. Further, it should be considered that this study includes a small number of patients (36 investigated and 16 transplanted).

\section{Conclusion}

In this retrospective study we could show that the multimodality approach of RFA following TACE in HCC patients awaiting liver transplantation might be effective in decreasing the drop-out rate from the waiting list. Moreover, this combined therapy results in high rates of tumor necrosis as evaluated in the histopathological analysis of the explanted livers. These promising pathological findings warrant further prospective randomized trials - including multiple transplantation centers - to confirm if there is a benefit of a multimodality approach in comparison to a single-treatment approach in bridging patients on a waiting list.

\section{References}

1 Jemal A, Bray F, Center MM, Ferlay J, Ward E, Forman D: Global cancer statistics. CA Cancer J Clin 2011;61:69-90.

$\checkmark 2$ Bruix J, Sherman M, Llovet JM, Beaugrand M, Lencioni R, Burroughs AK, Christensen E, Pagliaro L, Colombo M, Rodes J: Clinical management of hepatocellular carcinoma. Conclusions of the Barcelona 2000 EASL Conference. European Association for the Study of the Liver. J Hepatol 2001;35:421-430.

- 3 El-Serag HB, Rudolph KL: Hepatocellular carcinoma: epidemiology and molecular carcinogenesis. Gastroenterology 2007;132: 2557-2576

4 Lee FT Jr: Treatment of hepatocellular carcinoma in cirrhosis: locoregional therapies for bridging to liver transplant. Liver Transpl 2007;13:S24-26.

5 Bargellini I, Vignali C, Cioni R, Petruzzi P, Cicorelli A, Campani D, De Simone P, Filipponi F, Bartolozzi C: Hepatocellular carcinoma: CT for tumor response after transarterial chemoembolization in patients exceeding Milan criteria - selection parameter for liver transplantation. Radiology 2010; 255:289-300.

6 Bismuth H, Majno PE, Adam R: Liver transplantation for hepatocellular carcinoma. Semin Liver Dis 1999;19:311-322.

7 Sandroussi C, Dawson LA, Lee M, Guindi M, Fischer S, Ghanekar A, Cattral MS, McGilvray ID, Levy GA, Renner E, Greig PD, Grant DR: Radiotherapy as a bridge to liver transplantation for hepatocellular carcinoma. Transpl Int 2010;23:299-306.

Multimodality Treatment for Early-Stage HCC
-8 Mazzaferro V, Regalia E, Doci R, Andreola S, Pulvirenti A, Bozzetti F, Montalto F, Ammatuna M, Morabito A, Gennari L: Liver transplantation for the treatment of small hepatocellular carcinomas in patients with cirrhosis. N Engl J Med 1996;334:693-699.

-9 Yao FY, Bass NM, Nikolai B, Davern TJ, Kerlan R, Wu V, Ascher NL, Roberts JP: Liver transplantation for hepatocellular carcinoma: analysis of survival according to the intention-to-treat principle and dropout from the waiting list. Liver Transpl 2002;8:873883.

10 Yao FY, Hirose R, LaBerge JM, Davern TJ 3rd, Bass NM, Kerlan RK Jr, Merriman R, Feng S, Freise CE, Ascher NL, Roberts JP: A prospective study on downstaging of hepatocellular carcinoma prior to liver transplantation. Liver Transpl 2005;11:1505-1514.

-11 Lu DS, Yu NC, Raman SS, Lassman C, Tong MJ, Britten C, Durazo F, Saab S, Han S, Finn R, Hiatt JR, Busuttil RW: Percutaneous radiofrequency ablation of hepatocellular carcinoma as a bridge to liver transplantation. Hepatology 2005;41:1130-1137.

12 Mazzaferro V, Battiston C, Perrone S, Pulvirenti A, Regalia E, Romito R, Sarli D, Schiavo M, Garbagnati F, Marchiano A, Spreafico C, Camerini T, Mariani L, Miceli R, Andreola $S$ : Radiofrequency ablation of small hepatocellular carcinoma in cirrhotic patients awaiting liver transplantation: a prospective study. Ann Surg 2004;240:900-909.
13 Bruix J, Sherman M: Management of hepatocellular carcinoma. Hepatology 2005;42: 1208-1236.

14 Blum HE: Hepatocellular carcinoma: therapy and prevention. World J Gastroenterol 2005;11:7391-7400.

15 Herrero JI, Sangro B, Pardo F, Quiroga J, Inarrairaegui M, Rotellar F, Montiel C, Alegre F, Prieto J: Liver transplantation in patients with hepatocellular carcinoma across Milan criteria. Liver Transpl 2008;14:272278

16 Yao FY, Kinkhabwala M, LaBerge JM, Bass NM, Brown R Jr, Kerlan R, Venook A, Ascher NL, Emond JC, Roberts JP: The impact of pre-operative loco-regional therapy on outcome after liver transplantation for hepatocellular carcinoma. Am J Transplant 2005;5: 795-804.

17 Kim JH, Won HJ, Shin YM, Kim SH, Yoon HK, Sung KB, Kim PN: Medium-sized (3.1$5.0 \mathrm{~cm}$ ) hepatocellular carcinoma: transarterial chemoembolization plus radiofrequency ablation versus radiofrequency ablation alone. Ann Surg Oncol 2011;18:1624-1629.

18 Kim JW, Kim JH, Won HJ, Shin YM, Yoon HK, Sung KB, Kim PN: Hepatocellular carcinomas $2-3 \mathrm{~cm}$ in diameter: transarterial chemoembolization plus radiofrequency ablation vs. radiofrequency ablation alone. Eur J Radiol 2012;81:e189-193.

19 Meza-Junco J, Montano-Loza AJ, Liu DM, Sawyer MB, Bain VG, Ma M, Owen R: Locoregional radiological treatment for hepatocellular carcinoma; which, when and how? Cancer Treat Rev 2012;38:54-62. 
20 Rossi S, Garbagnati F, Lencioni R, Allgaier HP, Marchiano A, Fornari F, Quaretti P, Tolla GD, Ambrosi C, Mazzaferro V, Blum HE, Bartolozzi C: Percutaneous radiofrequency thermal ablation of nonresectable hepatocellular carcinoma after occlusion of tumor blood supply. Radiology 2000;217: 119-126.

-21 Bloomston M, Binitie O, Fraiji E, Murr M, Zervos E, Goldin S, Kudryk B, Zwiebel B, Black T, Fargher S, Rosemurgy AS: Transcatheter arterial chemoembolization with or without radiofrequency ablation in the management of patients with advanced hepatic malignancy. Am Surg 2002;68:827-831.

-22 Kirikoshi H, Saito S, Yoneda M, Fujita K, Mawatari H, Uchiyama T, Higurashi T, Goto A, Takahashi H, Abe Y, Inamori M, Kobayashi N, Kubota K, Sakaguchi T, Ueno N, Nakajima A: Outcome of transarterial chemoembolization monotherapy, and in combination with percutaneous ethanol injection, or radiofrequency ablation therapy for hepatocellular carcinoma. Hepatol Res 2009;39: 553-562.

23 Minami Y, Kudo M: Radiofrequency ablation of hepatocellular carcinoma: a literature review. Int J Hepatol 2011;2011:104685.

-24 Veltri A, Moretto P, Doriguzzi A, Pagano E, Carrara G, Gandini G: Radiofrequency thermal ablation after transarterial chemoembolization as a combined therapy for unresectable non-early hepatocellular carcinoma. Eur Radiol 2006;16:661-669.

-25 Ashoori N, Paprottka P, Trumm C, Bamberg F, Kolligs FT, Rentsch M, Reiser MF, Jakobs TF: Multimodality treatment with conventional transcatheter arterial chemoembolization and radiofrequency ablation for unresectable hepatocellular carcinoma. Digestion 2011;85:18-26.

26 Gupta S, Wallace MJ, Cardella JF, Kundu S, Miller DL, Rose SC: Quality improvement guidelines for percutaneous needle biopsy. J Vasc Interv Radiol 2010;21:969-975.
Figueras J, Jaurrieta E, Valls C, Ramos E, Serrano T, Rafecas A, Fabregat J, Torras J: Resection or transplantation for hepatocellular carcinoma in cirrhotic patients: outcomes based on indicated treatment strategy. J Am Coll Surg 2000;190:580-587.

28 Maluf D, Fisher RA, Maroney T, Cotterell A, Fulcher A, Tisnado J, Contos M, Luketic V, Stravitz R, Shiffman M, Sterling R, Posner $\mathrm{M}$ : Non-resective ablation and liver transplantation in patients with cirrhosis and hepatocellular carcinoma: safety and efficacy. Am J Transplant 2003;3:312-317.

29 Llovet JM, Fuster J, Bruix J: Intention-totreat analysis of surgical treatment for early hepatocellular carcinoma: resection versus transplantation. Hepatology 1999;30:14341440.

30 Yao FY, Bass NM, Nikolai B, Merriman R, Davern TJ, Kerlan R, Ascher NL, Roberts JP: A follow-up analysis of the pattern and predictors of dropout from the waiting list for liver transplantation in patients with hepatocellular carcinoma: implications for the current organ allocation policy. Liver Transpl 2003;9:684-692.

- 31 Cheng SJ, Freeman RB Jr, Wong JB: Predicting the probability of progression-free survival in patients with small hepatocellular carcinoma. Liver Transpl 2002;8:323-328.

32 Freeman RB, Edwards EB, Harper AM: Waiting list removal rates among patients with chronic and malignant liver diseases. Am J Transplant 2006;6:1416-1421.

33 Fontana RJ, Hamidullah H, Nghiem H, Greenson JK, Hussain H, Marrero J, Rudich S, McClure LA, Arenas J: Percutaneous radiofrequency thermal ablation of hepatocellular carcinoma: a safe and effective bridge to liver transplantation. Liver Transpl 2002;8: 1165-1174.

34 Cillo U, Vitale A, Grigoletto F, Gringeri E, D’Amico F, Valmasoni M, Brolese A, Zanus G, Srsen N, Carraro A, Burra P, Farinati F, Angeli P, D'Amico DF: Intention-to-treat analysis of liver transplantation in selected, aggressively treated HCC patients exceeding the Milan criteria. Am J Transplant 2007;7: 972-981.
35 Maddala YK, Stadheim L, Andrews JC, Burgart LJ, Rosen CB, Kremers WK, Gores G: Drop-out rates of patients with hepatocellular cancer listed for liver transplantation: outcome with chemoembolization. Liver Transpl 2004;10:449-455.

36 Bharat A, Brown DB, Crippin JS, Gould JE, Lowell JA, Shenoy S, Desai NM, Chapman WC: Pre-liver transplantation locoregional adjuvant therapy for hepatocellular carcino$\mathrm{ma}$ as a strategy to improve long-term survival. J Am Coll Surg 2006;203:411-420.

- 37 Lesurtel M, Mullhaupt B, Pestalozzi BC, Pfammatter T, Clavien PA: Transarterial chemoembolization as a bridge to liver transplantation for hepatocellular carcinoma: an evidence-based analysis. Am J Transplant 2006;6:2644-2650.

38 Buscarini L, Buscarini E, Di Stasi M, Vallisa D, Quaretti P, Rocca A: Percutaneous radiofrequency ablation of small hepatocellular carcinoma: long-term results. Eur Radiol 2001;11:914-921.

-39 Lencioni RA, Allgaier HP, Cioni D, Olschewski M, Deibert P, Crocetti L, Frings $\mathrm{H}$, Laubenberger J, Zuber I, Blum HE, Bartolozzi C: Small hepatocellular carcinoma in cirrhosis: randomized comparison of radiofrequency thermal ablation versus percutaneous ethanol injection. Radiology 2003; 228:235-240.

40 Marin HL, Furth EE, Olthoff K, Shaked A, Soulen MC: Histopathologic outcome of neoadjuvant image-guided therapy of hepatocellular carcinoma. J Gastrointestin Liver Dis 2009; 18:169-176.

41 Dromain C, de Baere T, Elias D, Kuoch V, Ducreux M, Boige V, Petrow P, Roche A, Sigal R: Hepatic tumors treated with percutaneous radiofrequency ablation: $\mathrm{CT}$ and $\mathrm{MR}$ imaging follow-up. Radiology 2002;223: 255-262. 